\title{
BUILDING SURVEY AND ENERGY MODELLING: AN INNOVATIVE RESTORATION PROJECT FOR CASA DEL FASCIO IN COMO
}

\author{
A. Buda ${ }^{1}$, S. Mauri ${ }^{1}$ \\ ${ }^{1}$ Politecnico di Milano, ABC Department - alessia.buda@polimi.it; sara.mauri@ polimi.it
}

KEY WORDS: Modern Architecture, Restoration, Energy Efficiency, Building Survey, Energy Simulation

\begin{abstract}
:
Historic buildings are fragile systems to be managed and protected during time: in the task of heritage restoration, efficiency improvement interventions should enable a more sustainable building conservation and use. Such measures might be defined within the combination of building survey and energy performance simulation. A good knowledge of materials and physics characteristics is fundamental to weigh correctly any improvement intervention. This can be supported also by documentary research and diagnostics, to detect existing resources and conservation issues. However, how to match all collected qualitative and quantitative data with a building energy model is still an open question. Energy simulation alone gives a partial vision of heritage needs, excluding information which do not affect the thermal performance of the model; on the contrary, a whole building approach is necessary for defining restoration interventions. With the aim of suggesting a methodology to combine both fields of investigation, a case study has been chosen to our purpose: Giuseppe Terragni's Casa del Fascio (1936). A multidisciplinary process with the combination of building survey, monitoring campaign, on-site investigation and energy modelling has been functional to the understanding of the real building needs and the definition of interventions. Furthermore, the analysis has given to the rediscover of Terragni's microclimatic control system (not more existing), leading to the choice of reinventing - in a modern way - the existing devices (as curtains), well-balanced on building needs.
\end{abstract}

\section{INTRODUCTION}

\subsection{Building survey and energy modelling for historic buildings}

This study aims to present a methodology for planning energy improvement measures based on a combination of different knowledge in a whole building approach.

In the last decade, the enhancement of energy efficiency for existing buildings, for historic heritage, is a widely discussed topic among the scientific community. How to balance sustainability and energy efficiency needs, pushed by EU Directives (EPBD 2010/31/EC, translated in the italian L.D. 90/2013) with the aim of preserving our heritage (L.D. 42/2004) is still an open question.

Historic buildings, which correspond to about a quarter of the existing European stock (Eurostat Report 2016), have a plurality of meanings, construction types and functions, belonging to different climates and, therefore, presenting variable needs (Lucchi et al., 2013). Given the complexity of this issue, regulations allow the exclusion of listed building from performance requirements.

Hence, the focus of the question shifts from the achievement of standard values to a performance improvement which shall be "as much as possible". However, the lack of a shared decisionmaking methodology may generate the risk to not have a complete overview on both material preservation and energy efficiency aspects when approaching the project (Buda et al., 2018).

The recent European standard EN 16883:2017 and the MiBAC Guidelines for assessing retrofit interventions for historic buildings (MiBAC, 2015) try to fill the regulatory gap and to respond with an operational methodology. As suggested for each energy audit (EN 16247-2:2014), both procedures start from a detailed initial survey to provide a better understanding of the building physical and constructive characteristics. Survey data will be used then for the creation of an energy model, functional for the recognition of current performance and for the check of improvement scenarios.

Despite the attempt of the European standard to define a more detailed assessment procedure (with a previous set of project objectives and a risk assessment analysis), in both documents the survey phase seems to be understood as a collection of information purely related to energy performance. It causes the exclusion of other important aspects for the preservation, such as users' comfort, IAQ, building constructive and material history (e.g. presence of finishing, singularities of the construction worth to be preserved, etc.).

Moreover, existing tools to model the historic buildings performance are designed to evaluate new constructions. This implies a difficulty in including in the energy model nonstandard building characteristics (as the existence of passive conditioning systems or craft made building components) or decay problems (such as water infiltration, molds, thermal bridges, etc), simplifying and omitting important aspects to be instead considered for a good restoration project (Adhikari et al., 2013).

Also, on the choice of the calculation performance method, the two aforementioned Guidelines don't suggest nothing in particular. Current Italian laws about energy performance of buildings are mainly based on the static monthly calculations of the UNI/TS 11300 standard, but for historic buildings it is suggested by many authors the use of a more detailed dynamic simulation application (Ascione et al., 2017; Aste et al., 2018; Mancini et al., 2016). With the static method, although results are quickly produced, there are numerous problems, such as lack of adequate databases, inability to define more complex parameters such as infiltration rate, internal gains and accuracy of weather data fact. Instead, the dynamic one needs high level modeling skills. This is the most suitable tool for the purpose: it allows in fact a greater parametrization and calibration of the 
model respect to the real building behavior, adopting some 'corrective' parameters (EN ISO 52000-1:2017).

Hence, intervening on the built heritage, with due sensitivity and competence, is a very delicate task. It needs a careful evaluation of interventions. The only energy performance analysis is not enough in fact to make decisions on heritage assets. The exclusion of data which do not affect the thermal performance of the model can lead to planning energy-oriented interventions that could damage the existing building, in contrast to the principle of sustainable conservation.

In this decision process, the question therefore is how to combine data to have a complete picture of the project, able to balance all different aspects.

This study wants to show an integrated methodology, in which a coherent, coordinated and planned activity of study, a technical survey and energy modelling are combined for improving the building efficiency and users' comfort, with the least impact on its consistency.

However, nowadays it still missing a tool which brings together quantitative and qualitative aspects, important for developing a sustainable restoration project. Since the shown case, some methodological considerations and possible future research perspectives will therefore be promoted.

\section{METHODOLOGY}

From the above considerations, the ultimate objective of this work is to obtain, using different investigation techniques, an integrated operational methodology for the analysis of the building and for assess energy retrofit solutions.

The integration of geometric survey data, archival and historical research, microclimatic analysis, material and decay investigation are in fact all necessary in order to ensure the best conditions of use and conservation.

So, the method is made by distinct and defined phases. It starts from a knowledge phase, collecting all building information. Firstly, an identification of the building compositional structure (dimensional characteristics and compositional - architectural rules) is done. Then, these data are compared to those of a documental (bibliographical and archival) research to allow us identifying the building transformations, from its construction to nowadays. Drawings, photos or documents can, in fact, show what changes the construction suffered, for natural causes or to previous renovation and restoration works.

Moreover, an on-site survey accompanies this phase: not all the building transformations are documented or trackable, especially the less relevant ones linked to ordinary maintenance or users' comfort needs (such as the replacement of construction elements with others different in terms of purpose and function, the plug of channels, the spot insertion of plants, etc.). They should be checked and included in the design choice process.

After the on-site survey, attention will be paid to the building thermo-hygrometric characteristics and to the indoor microclimate conditions, investigated using suitable diagnostic equipment. Once they have been monitored, it will be possible to define the energetic profile of the building.

Finally, microclimate data will be used to run a dynamic simulation software for the evaluation of the building energy performance. The conditions at the present time will constitute a baseline to compare then several retrofit scenarios.

The choice of solutions to be assessed in the model will descend from the whole of documental research, on-site survey and diagnostic analysis.

\section{THE CASE STUDY: CASA DEL FASCIO IN COMO}

The proposed methodology is applied to a real case study: Casa del Fascio in Como. Known as "Palazzo Terragni" and listed from the 1986, it's one of the historic masterpieces of the Italian Modern Movement, designed by the rationalist architect Giuseppe Terragni.

The original project of the Casa del Fascio, dated 1928, envisaged a building that reflected the standards of the time, completely different from the one that was built (Mantero, 1969). The design process, which led to the final solution, lasted for some years: after more project proposals and troubled events related to the building site, the construction work started in July 1933 and ended in 1936, when it was inaugurated to host the local branch of the National Fascist Party. It was used as House of Fascism for a relatively short period: only nine years, from 1936 to 1945 , after the liberation of the city of Como from the Fascist Regime, during which the building was occupied by the Provincial Federations of the National Liberation Committee Parties. Since 1957, the building houses the provincial headquarters of the VI Legion of the Guardia di Finanza police, which still occupies it (Poretti, 1998; Artioli, 1989). There are now some rumours and a public petition about a change of use of the building, which could be turned into a museum (Silvestrini, 2017).

The case study is well-suited to the purpose of this research: after the initial will expressed by the Superintendence of Archaeology, Fine Arts and Landscape of Milan to restore the windows, the opportunity was taken to check also the building indoor microclimate conditions with the aim of drawing up an energy efficiency project.

The main characteristic of the intervention should have been to preserve the building as much as possible with low-impact interventions (Figure 1).

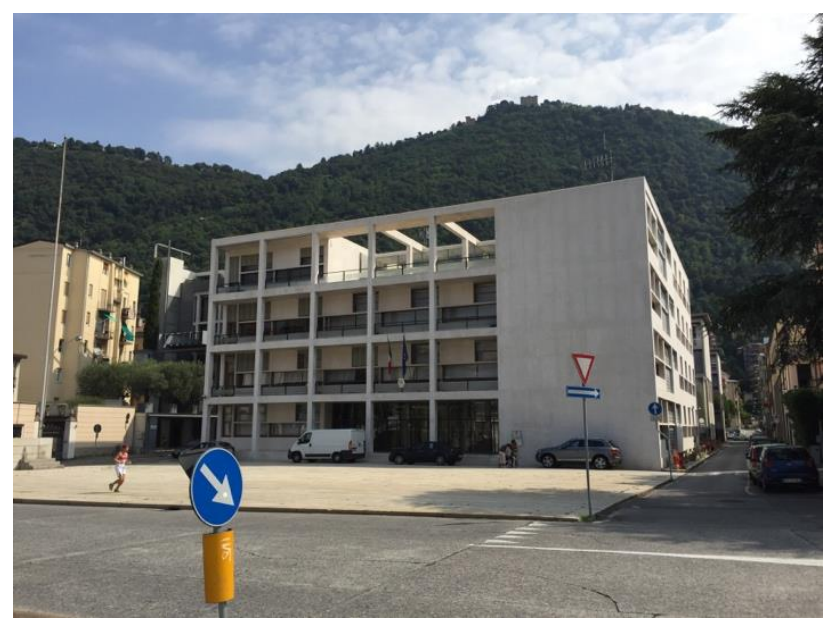

Figure 1. Casa del Fascio (Authors' capture, 2016)

\subsection{Architectural composition and geometrical studies}

The building survey starts from an exploration of the construction spatiality and the rules behind its architectural composition.

As well known, during totalitarianisms monumental architectures were often used as a propaganda of the Government ideologies. What their language has in common was the desire to privilege functional aspects of architecture, removing decoration and making sure that the form was subordinated to the function (Curtis, 2006). 
Hence, the rigor and the functionalism promoted by the Fascist regime are translated in the constructive shapes of Casa del Fascio. It appears as a purist abstraction, with flat roof and overhangs, flashings, gutters and drainpipes hidden from plain sight. This compact organism has four floors with a square plan, with a large central double height hall illuminated from above by skylight in concrete-frame glass block. This great covered courtyard, called "Salone delle Adunate", is the heart of the building (Figure 2); it's overlooked by the gallery of the first floor, which once connected the offices of the political secretariat, the "Sala del Direttorio" and the office of the political secretary.

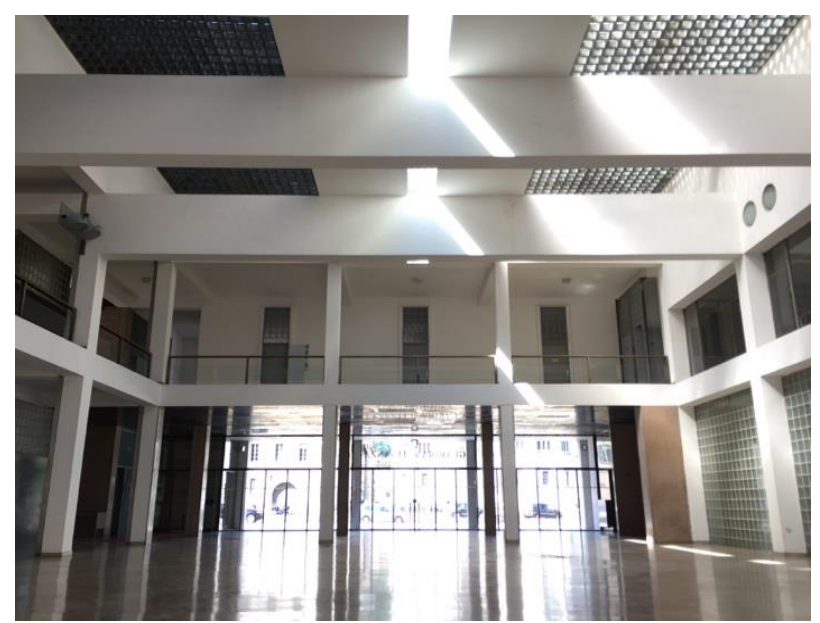

Figure 2. Salone delle Adunate (Authors' capture, 2016)

The second floor follows the distribution system of the first; the difference is that the gallery opens onto the roof of the internal atrium, characterized by a walkway that crosses it in the middle. From the corridor it is possible to access the rooms originally used as offices, administration and library (Figure 3).

On the top floor, two open galleries separate the building section initially intended for university groups from the one reserved for the archive and keeper's accommodation. This floor is served exclusively by the secondary staircase, while the other two can be reached via the main staircase, located to the right of the entrance (Terragni, 1936a).

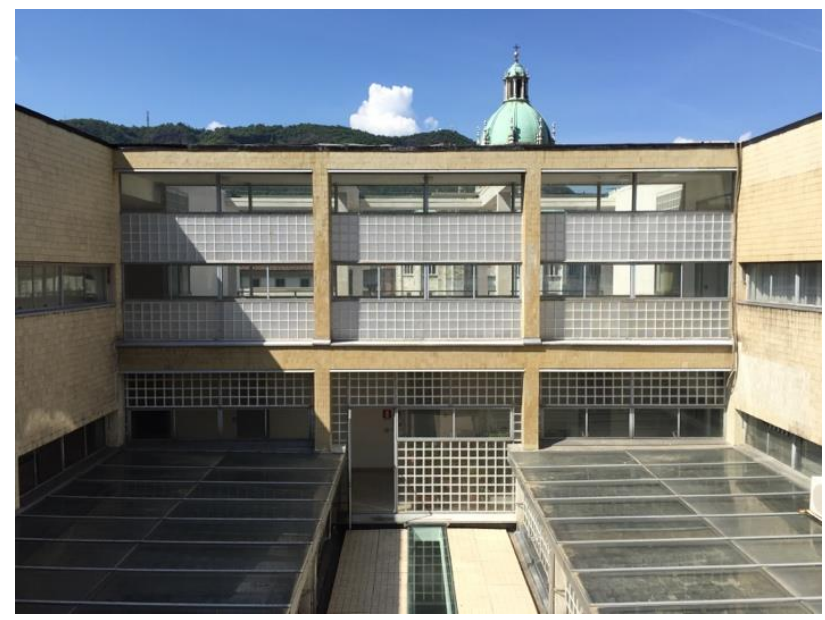

Figure 3. External atrium (Authors' capture, 2016)
The spatial tension between classical memories and modern architecture is evident in the internal distribution of spaces and in its geometrical proportions. For example, the size of the building is based on a 2:1 ratio: the height of $16,60 \mathrm{~m}$ is half of the base of $33,20 \mathrm{~m}$ (Saggio, 1995). Also the building orientation is not accidental: the alignment of the facades follows the axiality of the Roman centuriation (Cardo and Decumano) (Danesi et al., 1976). Through the graphical analysis carried out, it is also possible to state that the building is oriented along the orthogonal axes "North-West/South-East" and "North-East/South-West" with a rotation equal to about $25^{\circ}$ respect to the north geographic absolute (with coordinates $\left.45^{\circ} 48^{\prime} 44.4^{\prime \prime} \mathrm{N} 9^{\circ} 05^{\prime} 09.2^{\prime \prime} \mathrm{E}\right)$.

\subsection{Archival and Bibliographic research}

Acquiring information on the building is an essential condition for developing coherent intervention proposals. For this purpose, it's fundamental to start from a documental (bibliographical and archival) research to reconstruct the history of the building, from its construction to nowadays, highlighting all the transformations to which it was subjected.

About the case study, first a bibliographical research was carried out. A monographic number of Quadrante, magazine dedicated to the case study, allows to have a complete view of what were the design intents (Bontempelli et al., 1936). Terragni's will of differentiate the Casa del Fascio from the other architectures of the period is evident in the relation between solids and voids and in the choice of materials. Windows play an important role: their articulation is designed in relation to the building spans and create an ordered rhythm. An interesting solar and microclimatic study by Terragni is included also here. Since Ernst Neufert's studies on building insolation, a solar trends prospective study is presented; this one influenced the final positioning of the building and the withdrawal of the South-West façade (Piazza del Popolo). These measures would have achieved the objective of modifying the radiation and solar contribution during the summer period, favouring their entry during the winter months. Numerous written works have been consulted to reconstruct the history of the building. First, it should be emphasized that there are a large number of studies on architectural composition and critical readings that have contributed to its fame (Eisenmann, 2004). Others important studies are related to the investigation of the building site and the construction methods (Poretti, 1998). Still other documents are about the restoration works of the 1990s (Artioli, 1989). Except for the latter, the investigations carried out on the building have considered the Terragni's architecture in its making or in its immaterial aspects, neglecting the events in the eighty years of its lifespan that have radically changed its material consistency.

Fundamental in this regard was the investigation of archive collection, whose study was very complex and extended by virtue of the large number of documents held there (Busnelli et al., 2016).

The research has considered a wide range of documentation precious for our research: accounting and notarial documents, photographic material published and unpublished, local newspapers, private and administrative memories.

Particularly rich and never systematically explored is the "Archivio Municipale di Como" which preserves all the documentation produced by the municipal offices on post-war maintenance interventions. Another archive useful for this purpose was the one of the Superintendence of Archeology, Fine Arts and Landscape of Milan. It preserves documents, projects, cost estimate and photographs of the latest restoration 
works, linked to the institutional activity of historical-artistic protection carried out by the institution on the building from the 1986 (year in which it became a listed building) to this day. Here it was also possible to examine several drawings, including an architectural survey of the whole building, dated 1998.

In addition to the archival documents, the Giornali di Cantiere, written since 2005 by architect Luca Ambrosini (who is involved in the last restoration interventions), were analysed. These are documents in which are noted, day-to-day, the methods used to carry out ordinary and extraordinary maintenance, the number and attendance of workers and the cyclic problems that afflict the building. This information is fundamental to outline the last events that involved the Casa del Fascio.

After the reconstruction of the building lifespan, it was possible to reflect on the many changes, maintenance activities and restoration works that have affected it over the years. However, for a correct interpretation of these changes, the documental research is not enough: there are, in fact, numerous arbitrary and undocumented transformations that have been made, especially during the period when the building was not yet officially listed (which occurred only with the Ministerial Decree of 26th July 1986). Because a certain degree of secrecy of its destination and the lack of a well-timed recognition of its monumental value, the maintenance was mostly carried out by non-specialized labour; the result was the jeopardizing of the material consistency of the original building.

\subsection{On-site survey}

On-site surveys fill the gaps highlighted in the previous phase. They have made possible to describe accurately the building's materials and their conservation conditions (broken slabs, windows damages, etc,), in addition to the interior and exterior changes. This phase helped to verify the real technical feasibility of preliminary retrofitting scenarios.

Thanks to the guide of the architect Luca Ambrosini, profound connoisseur of the building, we have made several building surveys. Inspections took place between May 2015 to May 2016, in order to verify major problems during the whole period.

By reconstructing the sequence of interventions, it has been possible to observe how the building is changed during time.

The exterior is still characterized, as in the Terragni's project, using autarkic or traditional materials adapted to the new spirit of the time. The building, with a reinforced concrete construction system, presents external walls cladded with slabs of calcare di Botticino and translucent glass block walls. The external atrium walls were originally clad in ocher glassceramic tiles and translucent glass block walls. The first ones were gradually replaced with others in varnishing concrete, stoneware etc; the second ones have been progressively substituted by others different for treatment, transparency and proportion. The architectural composition of the façades, without decorative elements, is differently treated independently one from the other. During the survey we have found that frames are in wood or metal. Wooden ones account 10 typologies, different one from each other for their compositional and dimensional characteristics, in addition to the movement system of the openable parts. The metal windows are present in both perimeter and external atrium walls, where they were replaced during time.

A widespread use of glass block is noticeable, not only in the external walls, but also in the roof of the "Salone delle Adunate". This is composed of a skylight in concrete-frame glass block crossed in the middle of the longer side by a gallery. It was replaced in 1937 and, after several attempts to improve poor water tightness, it was covered with ondolux. In the 1990s it was subjected to a restoration, which was not decisive: hence, the decision to overlap the glass roof still in place causing a significative change of the interior lighting (Artioli, 1989).

The remaining part of roof is flat, partly used as a terrace, with a marble floor, and partly non-accessible, covered with a finishing layer of white cement grit tiles now replaced with eight bituminous sheaths layers (Terragni, 1936b) (Figure 4).

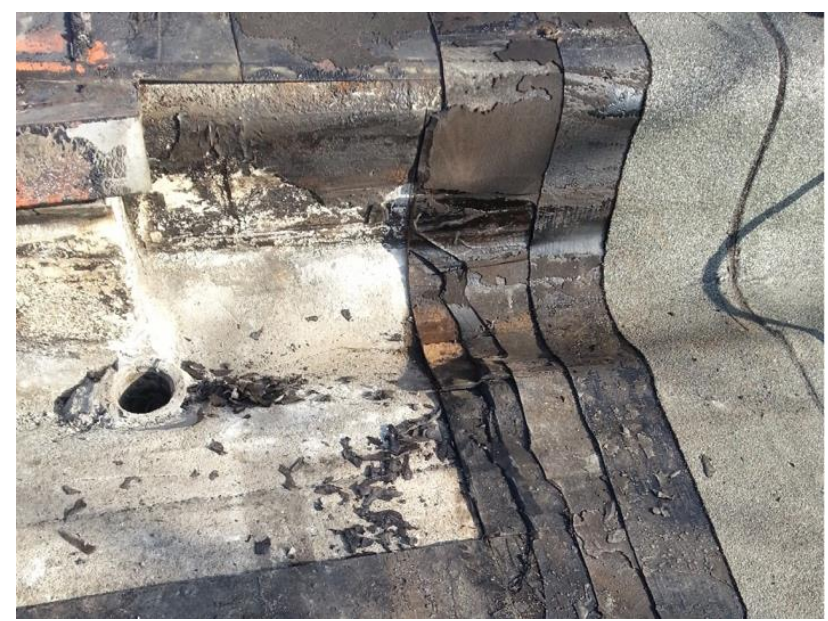

Figure 4. Non-accessible roof (Ambrosini’s photo, 2016)

From the analysis of the building state-of-art and from the comparison with what has been reported by the documentary resources, what has emerged is that interior spaces have remained almost the same during time with few exceptions, such as the offices of the "Fasci Femminili" now transformed into a chapel with a questionable colour choice. However, what has radically changed are the details and finishing that contribute to the way we perceive the building. For example, the original colour that distinguished the "Salone delle Adunate" was a blue - light green obtained by the overlap of two shades and not the current white (Pracchi et al., 2017).

Finally, an existing plants survey was done, necessary for the subsequent definition of interventions. Today, the heating system is characterized by the presence of a centralized boiler, located at the basement; terminal units are radiators (of different types) positioned in each room. During winter these are accompanied by temporary electric stoves, as reported by the building users. The historical bibliographic survey carried out previously allowed us to identify only some partial data concerning the electrical system and the technological elements that in the past constituted it.

This investigation has also revealed the existence of some solutions to mitigate the indoor microclimate conditions, but currently no longer in use. As we have found in the documental research, these systems were designed by Terragni himself mostly for the summer period. One of them is in fact a passive ventilation system, with vents distributed in the whole building (now closed); others are roller blinds (on the façade of Piazza del Popolo) and awnings (on via Pessina and on the perimeter walls of the external atrium), to screen from sunlight the large windows.

Thus, the technical complexity of the building is shown by the way in which materials are chosen and combined, as well as by the innovation of technological and mechanical systems. 
However, this experimental character has led to the failure or early disposal of devices designed by Terragni, and the onset of decay. For example, the correct construction techniques of the reinforced concrete structures, still little used in the 1930s, were not known: their installation without expansion joints has caused damage to the glass blocks and to the stone cladding of the façades (Artioli et al., 2009). Also the skylight in concreteframe glass block of the "Salone delle Adunate" has been repeatedly damaged by water and, as a consequence, subjected to indiscriminate substitutions with unsatisfactory results (Artioli, 1989). This situation has generated a lack of comfort, both in summer and winter, intensified by the high percentage of the transparent envelope.

During the survey, some customs officers' testimonies on the interventions recently carried out and on users' comfort perception have been collected. A better understanding of users' comfort for historic buildings implies in fact a fundamental understanding of how they work, in order to prevent and avoid deterioration processes, and unsuitable measures to control the indoor microclimate. It is the case of the insertion of temporary shading systems (e.g. venetian blinds) or some makeshift solutions for improving airtight.

Hence, although at first glance the Casa del Fascio appears ad an incorruptible monument, the direct survey highlighted a complex stratification of the architectural body, otherwise not traced back to a superficial analysis.

\subsection{Microclimate data and diagnostic analysis}

The building survey carried out on-site must be accompanied by a phase of instrumental diagnosis involving the properties of its components and the indoor microclimate conditions of the building. The high percentage of transparent envelope of the Modern Movement buildings was linked to the new possibility to control the internal comfort through innovation in plant. However, it appeared severely limited by the technological knowledge of the era, with results that are not always satisfactory in term of thermal performance of the building.

The analysis of the indoor thermo-hygrometric conditions of the Casa del Fascio was carried out using six microclimatic probes, located inside and outside the building according to the results of the preliminary psychrometric analysis. The latter was performed inside the building twice during the day: in morning and afternoon sessions, allowing to identify the points in which were the greatest daily thermal imbalances and, therefore, the most critical issues (Farinella et al., 2015).

In the next phase, the microclimatic probes were positioned where climatic conditions vary significantly between morning and afternoon: in total five internal points were identified and one external to the structure (1). The monitoring operations began on 13th December 2014 and ended on 5th May 2016, for a total of approximately one and half year.

The monitoring phase shown a strong influence of the external climate on the building thermal behaviour. The low thermal inertia characterizing the envelope doesn't correspond to an effective barrier against thermal and relative humidity variations. From the observation of the annual graph of daily average temperatures (Figure 5) it is clear expressed that the

\footnotetext{
(1) Probe $\mathrm{n}^{\circ} 1$ has been placed at the entrance; $\mathrm{n}^{\circ} 2$ inside the "Salone delle Adunate"; $\mathrm{n}^{\circ} 3$ in a room facing north-west with a damaged window, which remains open throughout the day and night; $n^{\circ} 4$ in the corridor of the top floor; $\mathrm{n}^{\circ} 5$ in the "Sala del Direttorio" on the first floor and, finally, $\mathrm{n}^{\circ} 6$ has been placed externally, on the open gallery of Piazza del Popolo, protected from direct sunlight.
}

days in which the values fall into the winter and summer comfort zones (provided by current legislation) are very limited. In winter, the heating system is only partially able to guarantee such comfort conditions; the summer period results to be the most critical, because there's no possibility of limiting overheating, due to the absence of solar shadings and to the disposal of the air conditioning system designed by Terragni. The highest recorded temperature within the building is around $35^{\circ} \mathrm{C}$. The graph of daily average relative humidity (Figure 6) confirms a strong sensitivity to external variations during the year, to which significant fluctuations of the indoor conditions correspond (Busnelli et al., 2016).

However, the internal microclimatic investigations have confirmed a strongly oscillating behaviour of temperatures and relative humidity. Anyway, it could be considered as "normal" for a structure such as the Casa del Fascio: large windows and thin walls in fact favour a strong thermal loss and, at the same time, guarantee a gain of thermal radiation during the raising of external temperatures and humidity.

The instrumental investigation ended detecting the thermal transmittance of north-west and north-east walls by means of a thermal flux-meter. These measurements and the related analysis of the data have been carried out in accordance with the indication provided by the international standard ISO 9869 (Farinella et al., 2015). Data were useful for the following dynamic modelling phase.

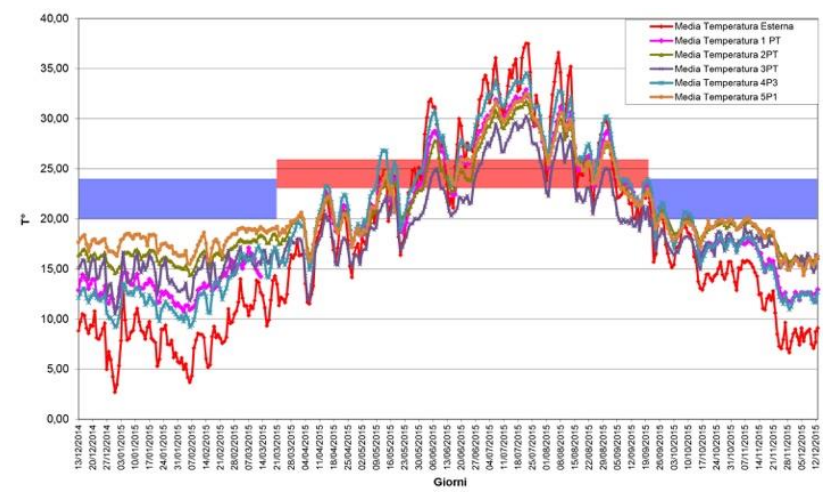

Figure 5. Temperature graph. Monitoring period from 13th December 2014 to 5th May 2016 (Busnelli et al., 2016)

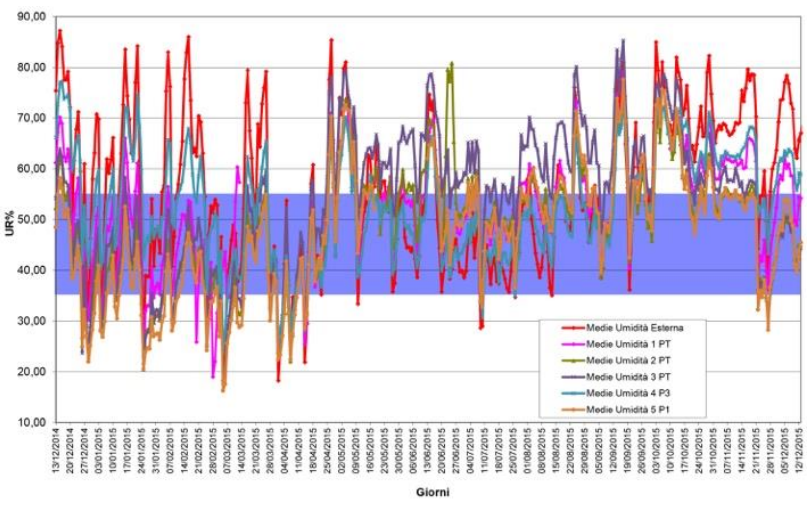

Figure 6. Relative Humidity graph. Monitoring period from 13th December 2014 to 5th May 2016 (Busnelli et al., 2016)

\subsection{Energy modelling of the building}

One of the objectives of this study is to achieve a repeatable methodology through which, not only a rigorous diagnosis 
could be carried out, but also a reliable calibration of a model can be achieved.

The EnergyPlus simulation engine is used in this research, validated by several authors and international papers also for historic buildings (Ascione, 2017; Adhikari et al., 2013; Aste et al., 2018). The building modelling has been realised using selected known data, relatively to the building. For modelers, most time is spent on troubleshooting and fine-tuning energy models. Hence, during the early modelling process, it is recommended to optimize the model, keeping it as simple as possible and make quick runs to identify problems.

The first step was the definition of the model geometry: it was defined and rotated according to the actual orientation in the space. It was also reconstructed the context with the related shading surfaces.

Then, the thermal zones were defined on the two levels (for a total of 31 zones to have a greater control of the space). The central atrium area has been considered as a unique area not heated, also comprising stairwells and corridors.

After that, it was described the envelope, assigning the thermal characteristics to opaque and transparent surfaces. The comprehension of the exact stratigraphy of material packages was possible through a combination of bibliographic research and direct observation, as well as a thermo-fluximeter diagnosis. Two different wall packages were identified, and all the recognized types of openings were inserted.

Once the model is geometrically concluded, it is necessary to ensure it becomes a reliable tool by using parameters to calibrate in according to the real microclimate data of the building. The building energy performance simulation can be performed not only to know the building consumptions in average operating conditions of a typical year, but also to determine its behaviour in the most critical conditions. The model was therefore verified both in winter and in summer in most critical moment. Among microclimatic data and model results, an average deviation of $20 \%$ was detected.

The following step was therefore the insertion of thermal loads. A schedule was then created for each zone with indicated electrical equipment, outdoor air flow rate and heating/cooling set-point.

All the internal loads (number of lights, computers, people, telephones, printers, radio, TV, etc.) have been entered in the electrical equipment parameter. In the winter verification period, the use of electric heaters was added, having a very strong weight on consumption. This datum was obtained by a cross-comparison between the power data of the various appliances and the consumption data of the bills.

For air changes, we have noticed previously that doors and windows are currently in a very degraded condition, so they are not completely openable. Hence, the value of external air flow was calculated based on the volume of the rooms and the infiltration factor through the windows. This data was also varied through a time schedule, according to the real use of the rooms.

As a heating/cooling set-point, a diversification has been made, creating two different time schedules according to the function of the space (collective or office) and the daily use.

The temperature values were derived crossing the measured data, given by the microclimatic probes and the psychrometer.

\subsection{Discussion}

Thanks to the whole of desk and on-site investigations, previously exposed, and to the energy model, that faithfully simulates the thermo-hygrometric behaviour of the building, it has been possible to formulate some hypotheses capable of reconciling the conservative objective with that of improving internal comfort.

Interventions have therefore been defined considering both winter and summer periods.

From our study, we have seen that winter time is less critical because the heating system is partially able to ensure acceptable comfort conditions.

Excluding therefore impacting interventions (such as the insulation of the flat roof), the restoration of wooden doors and windows was proposed. This operation has been (just partially) already realized, being the first objective of the Superintendence. Their restoration will allow not only to recover the possibility of windows opening/closing, but also to implement the glass thermal transmittance with its replacement. The simulation results show a $15 \%$ improvement compared to heating consumption. Considering the costs-benefits of this operation, although it would be expensive and complex with medium gains, the possibility to safeguard the integrity of a unique and unrepeatable system like this one is absolutely positive (Farinella et al., 2015).

The summer period, on the other hand, is the most critical since there is no possibility of limiting overheating except with the use of existing roller shutters which however obstruct the entry of natural light.

One of the aims of this study was therefore to evaluate the effectiveness of all those microclimatic solutions designed by Terragni, discovered during the previous investigations (the use of curtains on the facades most exposed to solar radiation, the inclusion of a summer air-conditioning system with inlet and outlet vents, etc.).

Hence, the energy model allows us to verify the actual contribution of all these systems in mitigating the peaks of temperature due to high solar radiation during the summer season. A first proof was the performance simulation of the previously existing sun protection systems. From a conservation point of view, their impact on the building is in fact very low because they are removable devices, already included in the project, able also to guarantee a correct modulation of the light inside.

The hypothesis of their restoration, accompanied by a correct management of the wooden blinds (present on all four facades) and by the insertion ex novo of internal curtains, lead to a lowering of the internal temperature of about $3^{\circ} \mathrm{C}$ (considering an average recorded value inside of $33^{\circ} \mathrm{C}$ ). The microclimate improvement is obvious, but it is not enough to ensure acceptable comfort conditions for workers (ASHRAE Standard 55-2013).

In view of this consideration, a further design solution was examined, aimed at shielding the incoming solar radiation from the skylight of the "Sala delle Adunate" by means of horizontal curtains. However, the results show a reduction of temperature of $1.5^{\circ} \mathrm{C}$ just in in the same space, while in the other rooms it makes just a smaller contribution. The realization of such an expensive and impactful intervention in terms of composition is therefore not justified by the improvements it offers in terms of thermal comfort (Busnelli et al., 2016).

\section{CONCLUSIONS}

Heritage conservation and renovation require a complex and multidisciplinary approach where the integration of several knowledge makes it possible to adopt well-balanced solutions with respect to the heritage values.

When improving the building sustainability, this means not necessarily achieving the energy performance levels that standard requires for new constructions but defining feasible 
measures according with the concepts of reversibility, recognizability, minimal impact and compatibility.

Within the restoration project, the definition of energy efficiency retrofit interventions starts from the recognition of the data concerning the geometric and material consistency of the building, functional to define restoration actions, but it also includes the building energy modelling, essential to evaluate and improve its performance.

However, the definition of an energy model, in a specific distinct software, implies that many data of the initial survey, if not related to the thermal analysis, are simplified to reduce the run time of the simulation, with the risk of neglecting important elements for a correct understanding of the building needs.

The prior objective of this study was to outline a multidisciplinary methodology, able to demonstrate how an integrated and critical use of input data, acquired through direct and indirect survey sources, could create a valid decisional and design support for the definition of energy improvement and restoration options of the built heritage.

In the exposed case study, the whole of architectural composition and geometrical studies, archival and bibliographic research and on-site survey made it possible to define a picture of building historical changes and stratifications.

All these results, together with the microclimatic and diagnostic analysis, allowed us to realize an optimized energy model, where identifying the current thermal performance data and assessing the energy impact of few feasible retrofit options, already verified from the conservation point of view. Hence, a prudent and careful choice of techniques and materials, also recovering and enhancing building elements designed by Terragni, was done.

The example however emphasizes the need for an integrable system to enclose all the information in a single tool.

Among the numerous ICT systems that are used for the improvement of the conservative process, promising possibilities are seen in the Building Information Modelling (BIM) process (Ciribini et al., 2014; Brumana et al., 2014), given the possibility to parameterize elements and to include detailed information in a single model.

Since the software is not specifically designed for historic buildings, it is not yet fitting for a professional use, remaining within the research field. The need to combine a parametric software with the energy modelling makes the challenge open. Many applications have provided significant enhancements to integrate whole-building energy dynamic simulation through the definition of ad hoc software plugins, in which energy analysis data, such as thermal properties of building materials and building space/functions can be defined. However, to run the energy simulation, it is still required to use a simplified version of the complete central model, that makes vain the effort spent at the beginning to gather all the information in a realistic model, losing the effectiveness of system interoperability too.

The creation of a virtual model of information, concerning both the historical material data of an architectural artefact, together with those relating to its energy performance therefore would be a very useful tool. It should be aimed at storing, updating and controlling data from different disciplinary sectors, becoming a fundamental point in the process of the building knowledge as well as in the design and project management phase.

\section{REFERENCES}

Adhikari, R.S., Lucchi, E., Pracchi, V., Rosina, E., 2013. Static and Dynamic Evaluation Methods for Energy Efficiency in Historical Buildings. PLEA $2013-29^{\text {th }}$ Conference,
Sustainable Architecture for a Renewable Future, Munich, $10^{\text {th- }}$ $12^{\text {th }}$ September 2013.

Artioli, A., 1989. Giuseppe Terragni: la Casa del Fascio di Como. Guida critica all'edificio; descrizione, vicende storiche, polemiche recenti restauri. BetaGamma, Roma.

Artioli, A., Adamo, D., Ambrosini, L., Longatti, M., 2009. Palazzo Terragni ovvero ex Casa del Fascio di Como (19321936) di G. Terragni. Esperienze di lavoro verso una conservazione programmata. Conservare l'architettura. Conservazione programmata per il patrimonio architettonico del XX secolo. Electa, Milano, 161-168.

Ascione, F., Ceroni, F., De Masi, R.F., De Rossi, F., Pecce, M.R., 2017. Historical buildings: Multidisciplinary approach to structural/energy diagnosis and performance assessment. Applied Energy, 185, 1517-1528.

ASHRAE Standard 55-2013. Thermal Environmental Conditions for Human Occupancy.

Aste, N., Adhikari, R.S., Buzzetti, M., Della Torre, S., Del Pero, C., Huerto C.H.E., Leonforte, F., 2019. Microclimatic monitoring of the Duomo (Milan Cathedral): Risks-based analysis for the conservation of its cultural heritage. Building and Environment, 148, 240-257.

Brumana, R., Oreni, D., Barazzetti, L., Banfi, F., Roncoroni, F., Previtali, M., Valente, R., 2014. Survey and HBIM of the Basilica di Collemaggio in L'Aquila for managing and planning conservation activities. ICT per il miglioramento del processo conservativo. Proceedings of the International Conference Preventive and Planned Conservation, Monza $5^{\text {th }}-9^{\text {th }} 2014,97-$ 112.

Buda, A., Pracchi, V., 2018. Potentialities and criticalities of different retrofit guidelines in their application on different case studies. EEHB 2018, Visby, 283-293.

Busnelli, F., Mauri, S., 2016. Fragilità di un'«architettura perfetta». Conoscenza degli aspetti materici e microclimatici della Casa del Fascio di Giuseppe Terragni a Como. Graduation Thesis, Politecnico di Milano.

Ciribini, A., Mastrolembo Ventura, S., Paneroni, M., 2014. La metodologia BIM a sostegno di un approccio integrato al processo conservativo. ICT per il miglioramento del processo conservativo. Proceedings of the International Conference Preventive and Planned Conservation, Monza $5^{\text {th }}-9^{\text {th }} 2014$, 111.

Curtis, W.J.R., 2006. L'architettura moderna del 1900. Phaidon, London, 364.

Danesi, S., Patetta, L., 1976. Il razionalismo e l'architettura in Italia durante il fascismo. Electa, Venezia.

Eisenman, P., 2004. Giuseppe Terragni: trasformazioni, scomposizioni, critiche. Quodlibet, Macerata.

EN 16247-2:2014. Energy audits - Part 2: Buildings.

EN 16883:2017. Conservation of cultural heritage - Guidelines for improving the energy performance of historic buildings, BSI The British Standards Institution 2017. 
EN ISO 52000-1:2017. Energy performance of buildings Overarching EPB assessment - Part 1: General framework and procedures (ISO 52000-1:2017)

EPBD Directive 2010/31/EU of the European Parliament and of the Council of 19 May 2010 on the energy performance of buildings (recast), 19th May 2010.

Eurostat, Census hub HC53, 2011.

Farinella, A., Fedeli, D., Stellini, M., 2015. "Il fascismo è una casa di vetro in cui tutti possono e devono guardare" L'analisi microclimatica della Casa del Fascio di Giuseppe Terragni a Como, Graduation Thesis, Politecnico di Milano.

Legge 90/2013 (italian legislative act). Conversione, con modificazioni, del decreto-legge 4 giugno 2013, n. 63. Disposizioni urgenti per il recepimento della Direttiva 2010/31/UE del Parlamento europeo e del Consiglio del 19 maggio 2010, sulla prestazione energetica nell'edilizia per la definizione delle procedure d'infrazione avviate dalla Commissione europea, nonché altre disposizioni in materia di coesione sociale" G.U. n. 181, 3rd August 2013.

Decreto Legislativo 42/2004 (legislative decree). Codice dei Beni culturali e del Paesaggio, 22 $2^{\text {th }}$ january 2004.

Lucchi, E., Pracchi, V., 2013. Efficienza energetica $e$ patrimonio costruito: la sfida del miglioramento delle prestazioni nell'edilizia storica. Maggioli, Santarcangelo di Romagna.

Mancini, F., Cecconi, M., De Sanctis, F., Beltotto, A., 2016. Energy retrofit of a historical building using simplified dynamic energy modelling. Energy Procedia, 101, 1119-1126.

Mantero, E., 1969. Giuseppe Terragni e la città del razionalismo italiano. Dedalo, Bari, 130-137.

MIBAC, 2015. Guidelines for the improvement of energy efficiency in cultural heritage.

Poretti, S., 1998. La Casa del Fascio di Como. Carocci, Roma.

Pracchi, V., Busnelli, F., Mauri, S., Ambrosini, L., 2017. Como: ottant'anni di vita della Casa del Fascio di Terragni. Ananke, 80, 75-81.

Bontempelli, M., Bardi, P. M., 1936. Quadrante. Documentario sulla Casa del Fascio di Como, 35-36, Messaggerie Italiane, Bologna.

Saggio, A., 1995. Giuseppe Terragni. Vita e opere. Laterza, Roma, 41-43.

Silvestrini, V., 2017. Architetture mitiche. E se l'ex Casa del Fascio di Terragni diventasse museo? Artribune. https://www.artribune.com/progettazione/architettura/2017/03/a rchitettura-petizione-ex-casa-del-fascio-terragni-como/

Terragni, G., 1936a. La costruzione della Casa del Fascio di Como. Quadrante, 35-36, Messaggerie Italiane, Bologna, 5-27.

Terragni, G., 1936b. Relazioni tecniche. Quadrante, 35-36, Messaggerie Italiane, Bologna, 38-54.
UNI/TS 11300-1:2014, Prestazioni energetiche degli edifici Parte 1: Determinazione del fabbisogno di energia termica dell'edificio per la climatizzazione estiva ed invernale. 